\title{
Cellulose Acetate Fabrics Loaded with Rhodamine B Hydrazide for Optical Detection of Cu(II)
}

\author{
Rania E. Morsi ${ }^{1,2, *}$, Moataz Elsawy ${ }^{1}$, Ilse Manet ${ }^{2}{ }^{-10}$ and Barbara Ventura ${ }^{2, *}$ \\ 1 Egyptian Petroleum Research Institute, Nasr City, Cairo 11727, Egypt; mo3taz_elsawy@yahoo.com \\ 2 Istituto per la Sintesi Organica e la Fotoreattività (ISOF), Consiglio Nazionale delle Ricerche (CNR), \\ 40129 Bologna, Italy; ilse.manet@isof.cnr.it \\ * Correspondence: raniaelsayed@yahoo.com or rania.morsi@isof.cnr.it (R.E.M.); \\ barbara.ventura@isof.cnr.it (B.V.)
}

Academic Editor: Chris E. Finlayson

Received: 30 June 2020; Accepted: 7 August 2020; Published: 17 August 2020

\begin{abstract}
In this work, different materials were fabricated from cellulose acetate, loaded with rhodamine $\mathrm{B}$ hydrazide and tested as $\mathrm{Cu}$ (II) optical sensor. We prepared membranes displaying a sub-micron porous structure using the phase inversion technique, clusters of fibers with varying diameter depending on the preparation procedure using electrospinning, and casted films presenting a smooth non porous structure. Loading of rhodamine B hydrazide on the fabrics after their production was found to be the best procedure to ensure the stability of the dye in the polymeric materials. Absorption and emission analysis of the solid substrates revealed the presence of the dye on the porous fabrics and allowed to choose the most suited materials and loading conditions to test their response towards $\mathrm{Cu}$ (II) ions. Reaction of the loaded rhodamine $\mathrm{B}$ hydrazide with $\mathrm{Cu}$ (II) was confirmed by absorption and emission spectroscopies and by confocal fluorescence imaging, through detection of the product rhodamine B. The results point to promising sensing applications of the prepared composite materials.
\end{abstract}

Keywords: cellulose acetate; rhodamine B hydrazide; optical sensing; membrane; fibers

\section{Introduction}

Fast, practical, and reliable detection of contaminants is a target of growing interest, as a result of the increased awareness and the enhanced levels of safety standards related to human health and the environment.

An important motivation is the growing number of diseases related to metal contaminated water. For example, long exposure to high copper concentrations can be toxic to living organisms and aqua-biological systems [1], thus, the development of efficient strategies for $\mathrm{Cu}$ (II) detection in water and environmental samples is a stringent challenge. Colorimetric or fluorimetric sensors are optical active dyes which show modifications of their absorption or fluorescence features upon interaction with the targeted species. Among these dyes, xanthenes, a class of photoactive materials, are widely used for targeting $\mathrm{Cu}(\mathrm{II})$, according to the ring opening mechanism induced by the presence of the metal ion, where the colorless and weakly fluorescent spiro form transforms into the open molecule, pink in color, and strongly fluorescent [2-4].

Immobilization of such molecules on supporting solid fabrics can facilitate and widen their range of applications. In general, integration of different materials with different properties results in a possibility of gaining additional features, as being amenable for sustainable use and recycling. The sensing molecules should be immobilized onto the support fabrics in a non-leaching way, ensuring at the same time their availability for the interaction with the metal ion. Research efforts have been 
recently devoted to the development of suitable supports and the optimization of immobilization techniques, providing potential capability for rapid, efficient, and low-cost sensing [5-7].

Most available supports are composed of polymeric materials fabricated with different morphological structures. Among them, porous membranes prepared by phase inversion showed several advantages and found interesting applications [8,9]. Electrospun polymeric nanofibers have also many interesting features due to their unique morphological structure, as the high porosity, the network structure with interconnected voids and the high surface area-to-volume ratio [10-13].

We previously reported the optimization of the immobilization of rhodamine B hydrazide (RBH) onto polymeric fabrics for the detection of $\mathrm{Cu}(\mathrm{II})$ ions in water through absorption and emission changes of the RBH dye that retained its optical features after being loaded into the porous matrices [14]. Polysulfone was used as scaffold material, fabricated in three different forms: casted films, porous membranes, and nanofibers prepared by solution casting, phase inversion, and electrospinning, respectively.

The aim of the current work is the development of biocompatible polymeric fabrics loading RBH for $\mathrm{Cu}$ (II) sensing applications using cellulose acetate, a natural polymer derivative, improving the sensory response of the loaded dye through the optimization of the fabrics morphology, and the loading procedure monitored by analysis of the dye absorption and emission properties.

\section{Results and Discussion}

\subsection{Fabrication of Cellulose Acetate Matrices}

Cellulose acetate (Scheme 1) is a polymer that can be used to produce diverse types of fabrics.

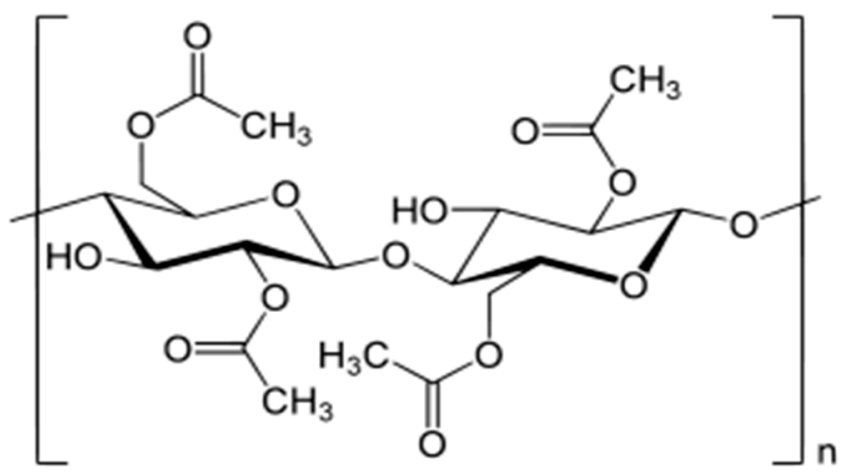

Scheme 1. Chemical structure of cellulose acetate.

In this work, cellulose acetate was fabricated as: (i) casted films by solution casting, (ii) porous membranes by phase inversion, and (iii) electrospun nanofibers by electrospinning technique. Morphological analysis with Scanning Electron Microscopy (SEM), showed that the three materials present very different surface features: the casted film has a smooth non-porous surface, the membrane has a porous surface with pore diameters in the sub-micron level and the electrospinning process from dimethylformamide (DMF) solution produced sub-micron fibers (Figure 1 for SEM images). Noticeably, the solvent and working conditions used in the electrospinning process greatly affect the morphology of the nanofibers [15-17] (Figure 2): the use of dichloromethane (DCM)/acetone mixture produced larger and flatter fibers (Figure $2 b$ ), with the macroscopic outcome of a soft fabric with cotton wool like texture. 
a

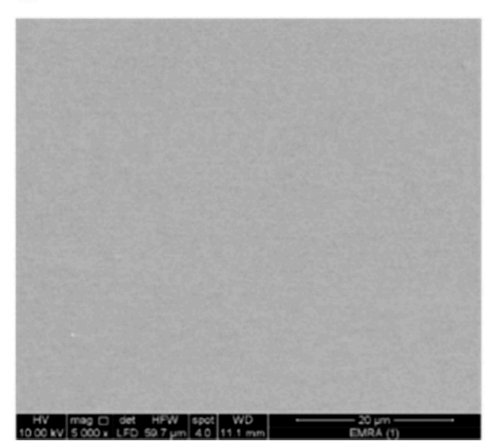

b

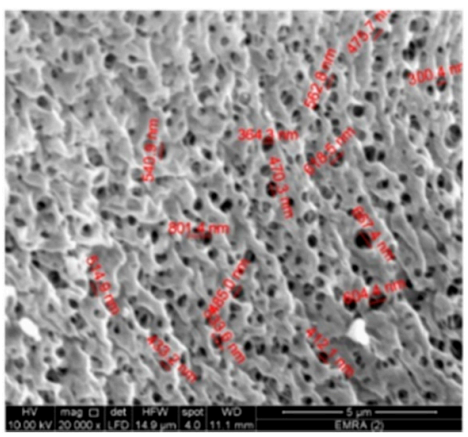

C

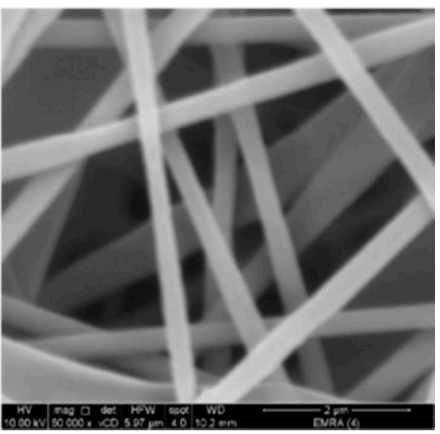

Figure 1. Scanning Electron Microscopy (SEM) images of the prepared cellulose acetate materials as: (a) casted film, (b) porous membrane, and (c) nanofibers from dimethylformamide (DMF).

a

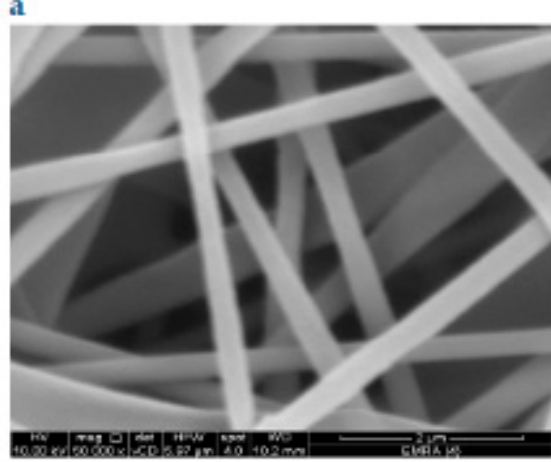

b

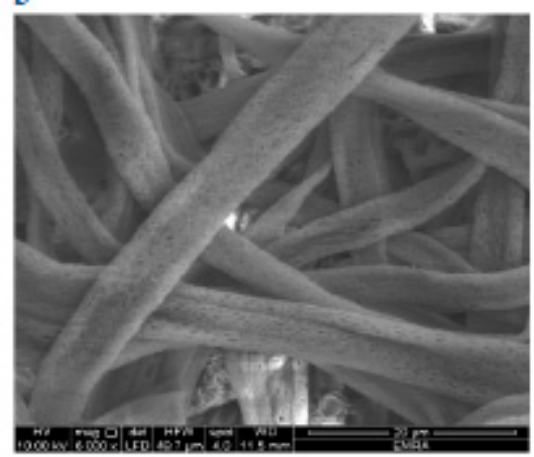

Figure 2. SEM images for the electrospun cellulose acetate nanofibers obtained in: (a) DMF and (b) dichloromethane (DCM)/acetone mixture.

2.2. Loading of RBH into the Cellulose Acetate Fabrics: Morphological and Spectroscopic Characterization

The chemical structures of RBH and its open form RB are shown in Scheme 2.<smiles>CCN(CC)c1ccc2c(c1)Oc1cc(N(CC)CC)ccc1C21c2ccccc2C(=O)N1N</smiles><smiles></smiles>

Scheme 2. Structure of Rhodamine B hydrazide ( $\mathrm{RBH}$, left) and Rhodamine B (RB, right).

Ethanol was chosen as a solvent for RBH since it is well absorbed into the cellulose acetate fabrics without solubilizing the polymer.

A preliminary spectroscopic characterization of $\mathrm{RBH}$ and its open form RB in ethanol has been performed. Absorption and emission features of the two forms, reported in Figures S1 and S2, were found to be similar to those observed in acetonitrile [14]. The main differences reside in a red-shifted emission (maximum at 560 vs. $524 \mathrm{~nm}$ ) for RBH and a blue shift of both absorption and emission bands (544 vs. $555 \mathrm{~nm}$ and 570 vs. $582 \mathrm{~nm}$, respectively) for RB in ethanol with respect to acetonitrile. Excited state lifetimes of 1.6 and 3.0 ns were measured for RBH and RB, respectively [18-20]. 
$\mathrm{RBH}$ was loaded onto the fabrics either by pre- or post-treatment, as described in the Materials and Methods section. The structural characteristics of both the cellulose acetate and $\mathrm{RBH}$, represented in Schemes 1 and 2, suggest an affinity between the dye and the polymer, given by electrostatic interactions and hydrogen bonding [21], due to the possibility of hydrophobic, hydrophilic and $\pi-\pi$ interactions in different moieties of their structures [22].

From a morphological analysis of the RBH loaded materials by means of SEM (Figures 3-5) it can be inferred that the loading of the dye, either by pre- or post-treatment, is not largely affecting the morphology of the materials, with the exception of a pore closure effect in the case of the phase inversion deposited membrane (Figure 4c).

a

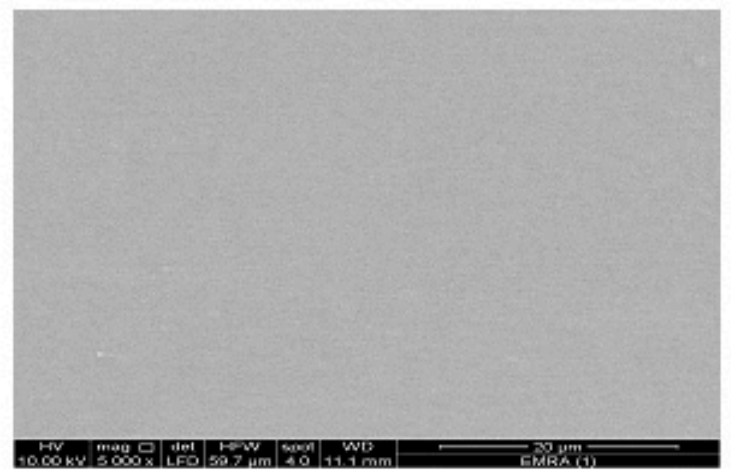

b

C
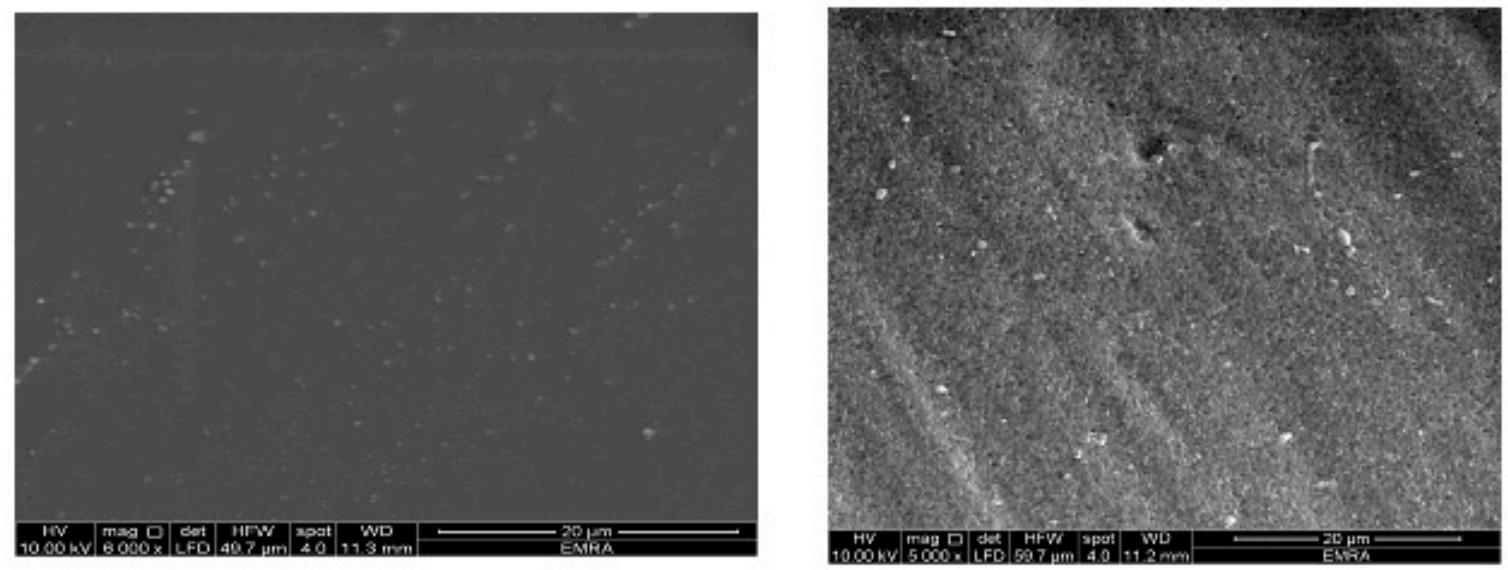

Figure 3. SEM images of the casted cellulose acetate film: (a) pure fabric, (b) fabric loaded with RBH by pre-treatment, and (c) fabric loaded with $\mathrm{RBH}$ by post-treatment.

In the case of $\mathrm{RBH}$ pre-loading in the materials, the embedded dye was found to be unstable in air, possibly due to the reaction with traces of acidity present in environmental aqueous vapor. For this reason, these materials have not been characterized from the photophysical point of view and a complete spectroscopic analysis has been performed only for the post-loaded fabrics. 
a

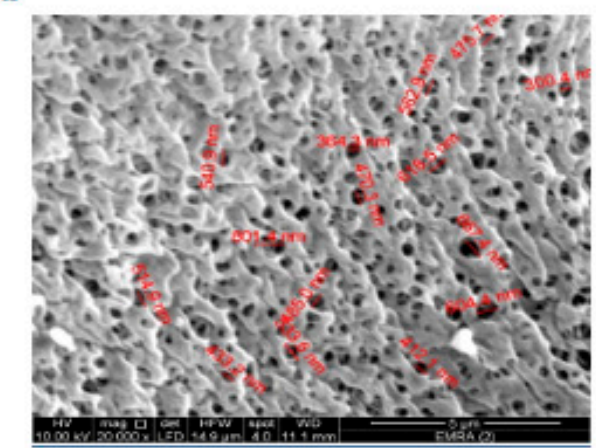

b
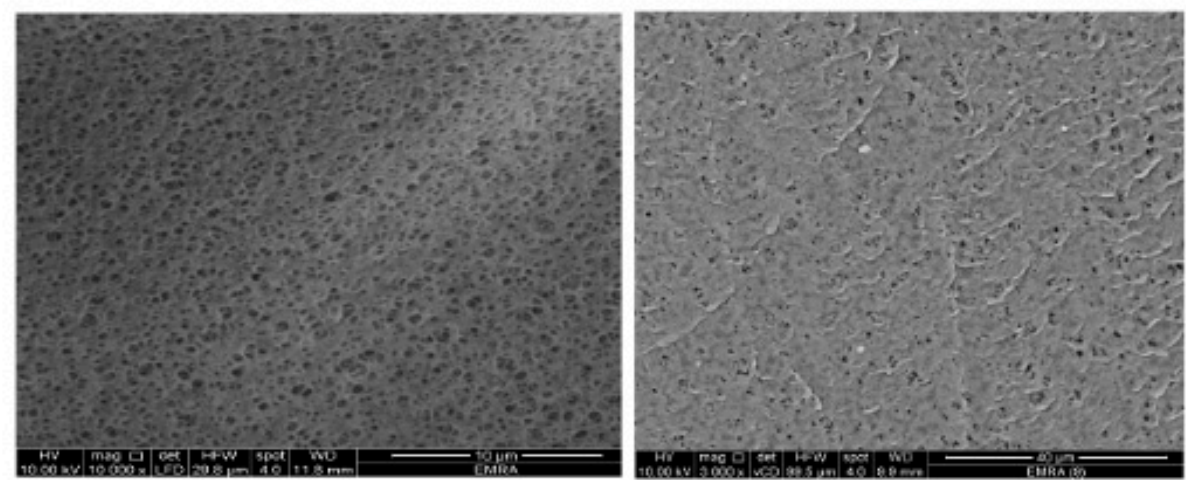

Figure 4. SEM images for the phase inversion deposited cellulose acetate membrane: (a) pure fabric, (b) fabric loaded with RBH by pre-treatment, and (c) fabric loaded with RBH by post-treatment.

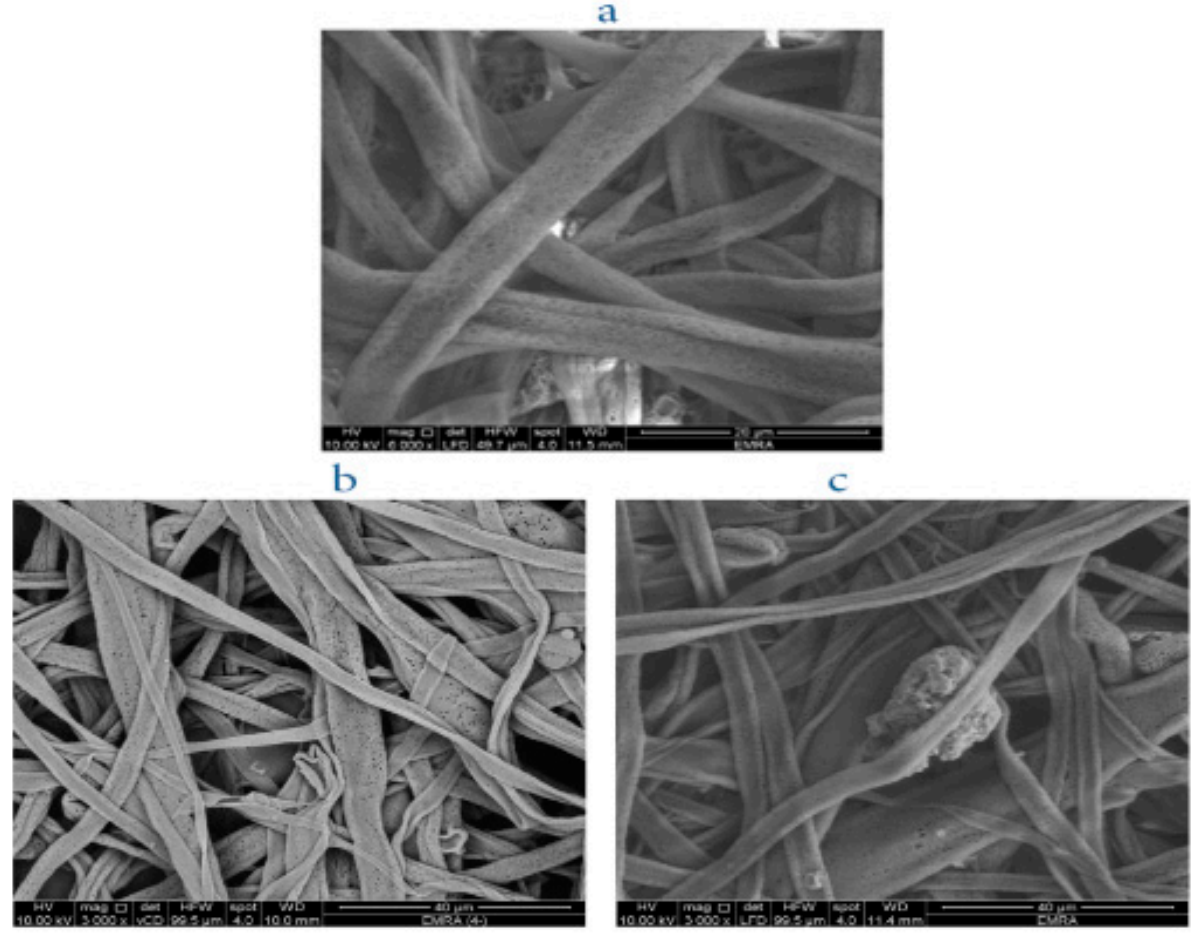

Figure 5. SEM images for the electrospun cellulose acetate fibers from DCM/acetone: (a) pure fabric, (b) fabric loaded with RHB by pre-treatment, and (c) fabric loaded with RHB by post-treatment.

Reflectance spectra of the bare materials and of the same materials loaded with $\mathrm{RBH}$ by post-treatment $(0.5$ and $1.0 \% w / w)$, acquired by means of an integrating sphere, are shown in Figure 6. In all the examined samples, the spectrum of the untreated polymer consists of an envelope of bands in 
the region $200-350 \mathrm{~nm}$. For all the treated materials, the loading of RBH was clearly confirmed by the appearance of the bands at 270 and $320 \mathrm{~nm}$, typical of the RBH dye (Figure 6). In order to achieve an approximately quantitative description, the spectra have been converted in absorbance, as a function of the diffuse reflectance $(f(R))$, by using the Kubelka-Munk equation [23] (Figure S3). An almost quantitative doubling of RBH absorption is observed in all cases upon increasing the percentage of loading from $0.5 \%$ to $1.0 \%$ (Figure S3). The highest degree of loading is observed in the most porous material, i.e., the phase deposited membrane (Figure $6 \mathrm{~b}$ and Figure S3b).
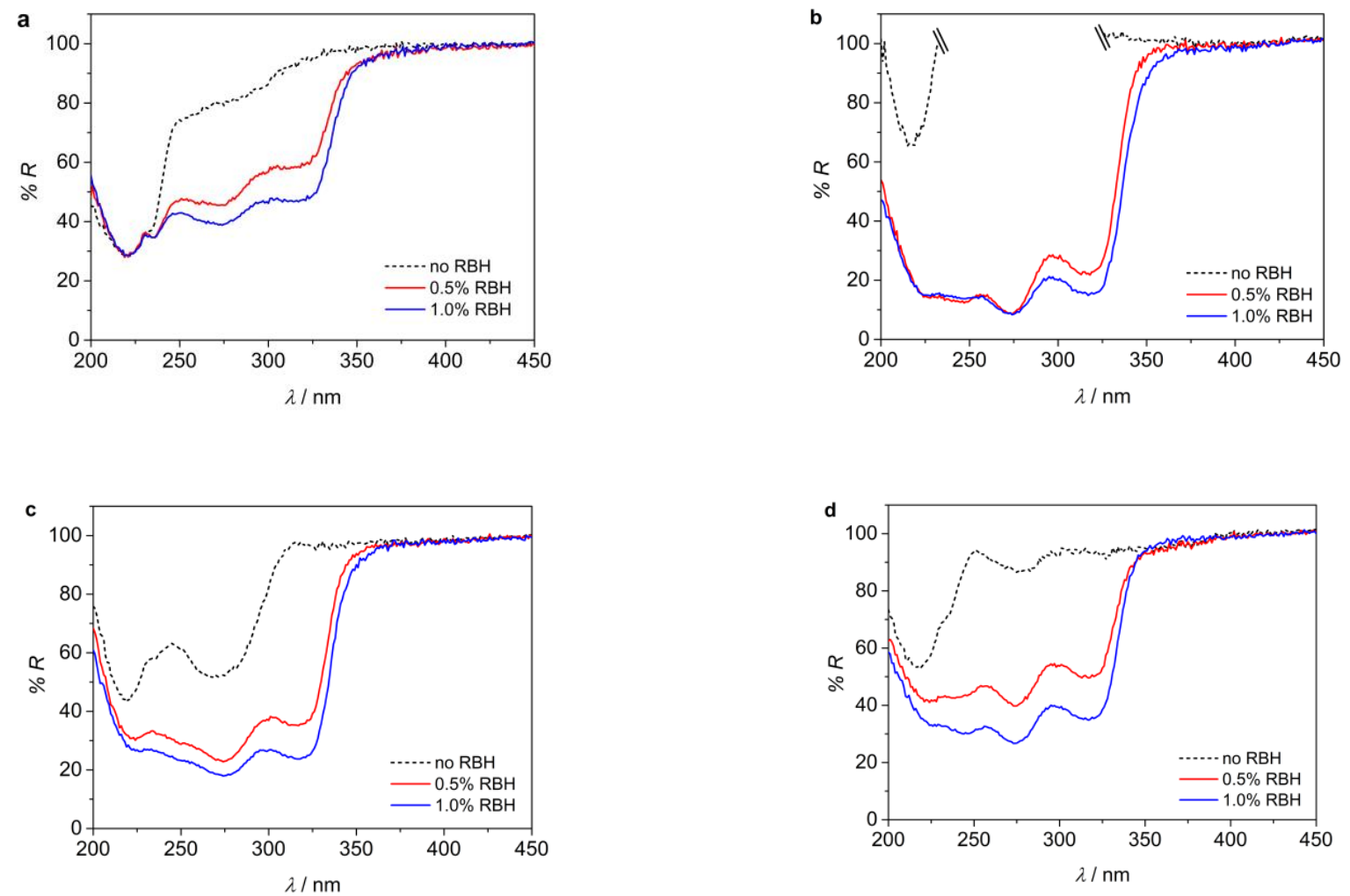

Figure 6. Reflectance spectra of samples with $0,0.5$, and $1 \%(w / w)$ post-loading of RBH: (a) casted film, (b) phase deposited membrane ${ }^{\S}$, (c) fibers from DMF, and (d) fibers from DCM/acetone.

Emission spectra have been collected, upon excitation at $320 \mathrm{~nm}$, for all samples (Figure S4). The bare polymeric material shows a weak emission in the $350-500 \mathrm{~nm}$ range in all cases, except for the sample of fibers obtained from DMF, where an intense and a well-defined band with maximum at $380 \mathrm{~nm}$ is observed (Figure S4c). Excitation spectra, collected at $430 \mathrm{~nm}$, show features resembling the polymer absorption bands (Figure S5 for selected examples).

The loading of RBH results in a clear emission band at $470 \mathrm{~nm}$, typical of the molecule, for porous membrane and fibers samples (Figure S4). In these samples, the emission from the polymer is suppressed and only the fluorescence from RBH is present, with a general trend towards an increased intensity for the higher degree of loading. On the contrary, the casted film loaded with RBH shows a weak emission from $\mathrm{RBH}$, comparable in intensity with the faint emission of the polymer, still observable (Figure S4a). This latter result indicates a non-optimal affinity or distribution of the dye on the polymeric support, probably due to the high smoothness of the surface. It can be noticed that a shoulder (or a band) at $580 \mathrm{~nm}$, typical of the open form RB, is appearing in all cases, overlapping with the RBH emission. This is due to the presence of traces of RB in the samples, easily detectable thanks to its emission properties, different from those of RBH [14]. Excitation spectra, measured at 500 and $600 \mathrm{~nm}$ for the porous membrane sample loaded with $1 \% \mathrm{RBH}$, confirmed that the band at $580 \mathrm{~nm}$ originates from RB (Figure S6), pointing to some degradation of the materials during the post-loading process [14]. 
In conclusion, the analysis allowed to ascertain that cellulose acetate is a good polymer for the loading of RBH with a post-treatment deposition, showing interesting morphological features, good stability with respect to degradation and retained optical properties of the dye. The porous samples and fibers were identified as the best materials to be used as scaffolds, and $1.0 \%$ loading has been chosen as the optimum condition.

In order to determine the response to $\mathrm{Cu}(\mathrm{II})$ of the selected membrane and fiber samples post-loaded with $\mathrm{RBH} 1 \%$, exposure to $\mathrm{CuCl}_{2}$ water solutions $(\mathrm{pH}=7)$ at different $\mathrm{Cu}$ (II) concentrations (1-200 ppm) was performed, leaving the samples for 1 night in contact with the copper solution. Reflectance spectra of the materials, recorded after exposure, reveal in all cases the appearance of a band with maximum at $560 \mathrm{~nm}$, with a general trend in its intensification upon increase of the copper concentration (Figure 7). The features of the new band lead to identify it as the main absorption band of RB, even if it is red-shifted, broader and more split with respect to the solution case (see Figure S2). These features can be ascribed to a high local concentration of the dye on the polymeric material [24]. Overall, the results testify the reaction of the deposited $\mathrm{RBH}$ with the $\mathrm{Cu}(\mathrm{II})$ ions present in solution, which leads to the opening of the spiro ring and formation of RB [25], and the trend in the absorption spectra points to a promising application of the prepared materials as colorimetric sensors for $\mathrm{Cu}(\mathrm{II})$. Moving towards a quantitative approach, the reflectance spectra have been converted in absorption spectra (Figure S7): absorbance values of the order of 0.1 are detected for the RB band at $560 \mathrm{~nm}$ at the maximum concentration of $\mathrm{Cu}$ (II). A quantitative evaluation cannot be performed due to the difficulty in determining the molar absorption coefficient of the dye inside the material and to the limitation of the spectrophotometric analysis to the surface of the porous sample. By considering the molar absorption coefficient of RB in solution [14], only a rough estimation of the local concentration of the dye can be performed, yielding a $\mu \mathrm{M}$ range. Notably, the material which shows the highest sensitivity, with a reliable detection of $\mathrm{Cu}(\mathrm{II})$ at $1 \mathrm{ppm}$, is that composed of fibers obtained from DCM/acetone (Figure 7c and Figure S7c). On the basis of this result, we can envisage for this material a limit of detection of the order of $0.1 \mathrm{ppm}$. It can be noticed that a second absorption band at ca. $715 \mathrm{~nm}$ appears, upon $\mathrm{Cu}(\mathrm{II})$ exposure, in all cases and it is more pronounced in the softer fiber material (fibers from DCM/acetone, Figure 7c and Figure S7c). It can be attributed to an aggregated form of the formed RB.

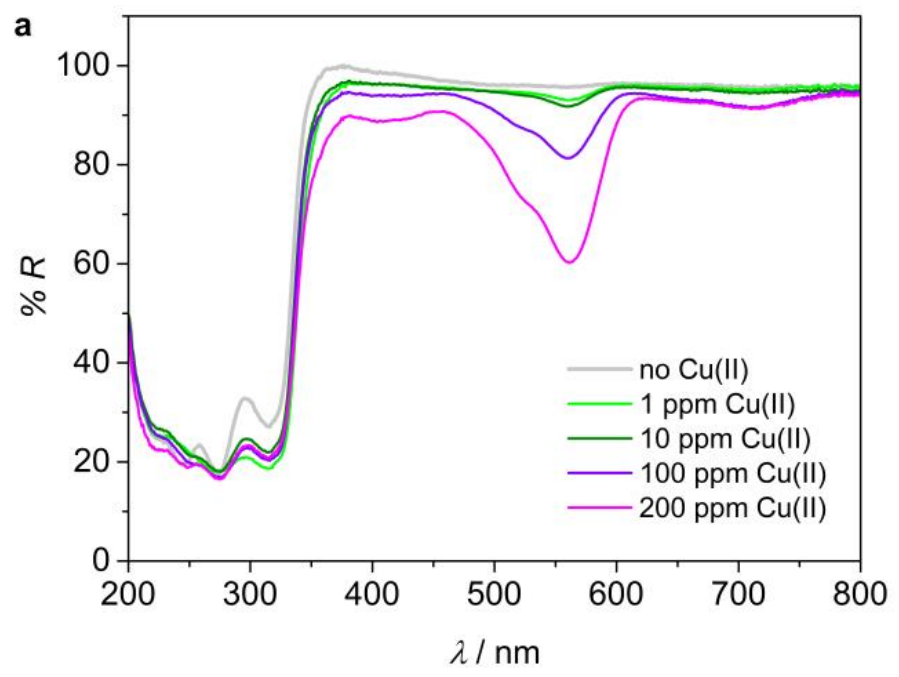

Figure 7. Cont. 

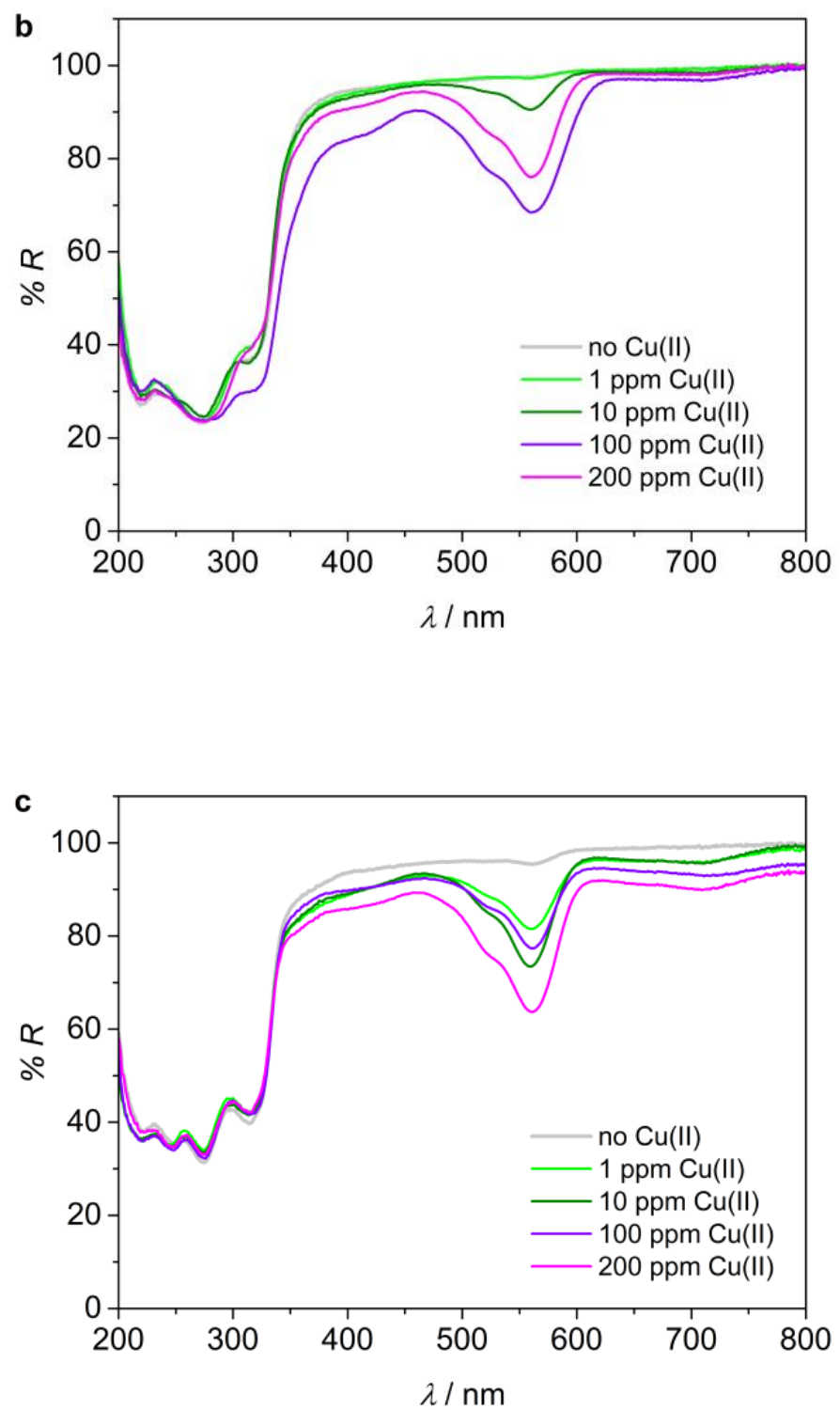

Figure 7. Reflectance spectra of the RBH loaded polymeric materials, prior and after 1 night immersion in $\mathrm{CuCl}_{2}$ water solutions $(\mathrm{pH}=7)$ at different $\mathrm{Cu}(\mathrm{II})$ concentrations: (a) porous membrane, (b) fibers from DMF, and (c) fibers from DCM/acetone.

Emission spectra have been recorded upon excitation at $320 \mathrm{~nm}$ (absorption maximum of RBH) and at $480 \mathrm{~nm}$ (selective excitation of the open form RB). The results are shown in Figures S8 and S9, as described in details below. Each spectrum is an average of two to four spectra taken in different areas of the solid materials, to reduce the effects of possible non-homogeneous distribution of the dye.

Excitation at $320 \mathrm{~nm}$ leads to prevalent excitation of RBH but also RB, formed upon reaction with $\mathrm{Cu}^{2+}$, is partially absorbing at this wavelength. The emission spectra thus present both emission bands of RBH and RB at 470 and $584 \mathrm{~nm}$, respectively. The trend of the relative intensity of the band at 584 $\mathrm{nm}$ with respect to the one at $470 \mathrm{~nm}$ has been analyzed as a function of the copper concentration (Figure S8). An increase of the ratio with the concentration of the $\mathrm{Cu}$ (II) solution is observed up to $100 \mathrm{ppm}$, whereas at $200 \mathrm{ppm}$ a decrease is occurring in all cases. This can be ascribed to the formation of aggregates of the produced RB that limit its emission output. 
The spectra obtained upon excitation at $480 \mathrm{~nm}$ are shown in Figure S9. An intensification of RB emission intensity following the increase of the $\mathrm{Cu}(\mathrm{II})$ concentration is observed in all cases, with the exception of an unusual behavior for the fibers obtained from DCM/acetone in contact with a 100 ppm copper solution (Figure S9c). It can be noticed that an apparent red-shift of the emission maximum is observed with the increase of the copper concentration, and that in the samples in contact with the higher amount of $\mathrm{Cu}(\mathrm{II})$ an additional emission band at ca. $760 \mathrm{~nm}$ is appearing. The former effect is due to the large increase of RB absorption (Figure 7c and Figure S7c) that leads to a re-absorption effect in the region of emission at around $600 \mathrm{~nm}$, while the latter feature can be ascribed to the formation of aggregates of RB on the material, when its concentration increases due to the reaction of RBH with $\mathrm{Cu}(\mathrm{II})$. Near-infrared (NIR) emission from RB aggregates, indeed, has been reported in the solid state or for high concentrated dyes entrapped into porous nanomaterials [24,26]. This outcome, already pointed out by the absorption data, is further confirmed by the excitation spectrum collected at $750 \mathrm{~nm}$ (Figure S10 for a selected case): an absorption profile different from that of RB (which is indeed observed upon collection at $620 \mathrm{~nm}$ ) is obtained, with a significant contribution in the spectral region around $700 \mathrm{~nm}$.

Emission lifetimes were measured for all the samples upon excitation at $331 \mathrm{~nm}$, and the results are summarized in Table S1. The decays are multi-exponential in all cases, likely due to different local environments and distributions of the dyes. They can be treated with good approximation with a bi-exponential fitting procedure (Table S1). Decays collected at $470 \mathrm{~nm}$, maximum of RBH emission, show a minor component with an average value of $2.4 \mathrm{~ns}$ and a major one (accounting for $50-70 \%$ of the decay) in the range 15-17 ns. Collection at $600 \mathrm{~nm}$, emission maximum of the open form RB, leads to detect a lifetime of ca. 3.4 ns whose weight increases with the increase of the $\mathrm{Cu}$ (II) concentration and a longer lifetime of 10-14 ns, whose value is generally decreasing with the $\mathrm{Cu}(\mathrm{II})$ increment. The short lifetimes measured at both wavelengths are in good agreement with those detected in solution for $\mathrm{RBH}$ and RB (1.6 ns and $3.0 \mathrm{~ns}$, respectively) while the longer components can be tentatively ascribed to aggregates or to re-absorption effects due to the high local concentration of the dyes [27,28]. The trend observed for relative amplitudes of the lifetimes measured at $600 \mathrm{~nm}$ confirm the occurrence of the recognition reaction in the materials.

Overall, the results point to a good response of the selected materials to $\mathrm{Cu}(\mathrm{II})$, with some drawbacks due to the formation of aggregates after the recognition reaction.

\subsection{Fluorescence Confocal Laser Scanning Microscopy}

Fluorescence Confocal Laser Scanning Microscopy (CLSM) imaging of the materials loaded with $1 \% \mathrm{RBH}$, before and after reaction with different amounts of $\mathrm{Cu}(\mathrm{II})$, has been performed. The images show that the dye is well distributed in the porous membrane and fibers. Figure 8 shows the confocal images of fibers obtained from DCM/acetone treated and not with increasing amounts of $\mathrm{Cu}$ (II), and the corresponding spectra of selected regions of interest for excitation at $405 \mathrm{~nm}$. The sample that has not been treated with $\mathrm{Cu}(\mathrm{II})$ displays a fluorescence spectrum similar to that of the closed $\mathrm{RBH}$ form. However, also in confocal imaging we discern a small presence of RB in the un-reacted material. In the treated samples the fluorescence spectra clearly show the appearance of the fluorescence of the open form (RB), peaking at ca. $580 \mathrm{~nm}$, and the relative $\mathrm{RB}$ intensity follows the amount of $\mathrm{Cu}$ present in solution. In Figure S11, images of the $\mathrm{Cu}(\mathrm{II})$ treated fibers show that the spectra in different regions of interest are very similar throughout the whole sample. Also the images displaying the fluorescence intensity ratio $\mathrm{I}_{(585 \mathrm{~nm})} / \mathrm{I}_{(480 \mathrm{~nm})}$ with the color scale ranging from 0 to 3 confirm the trend of the spectra. 

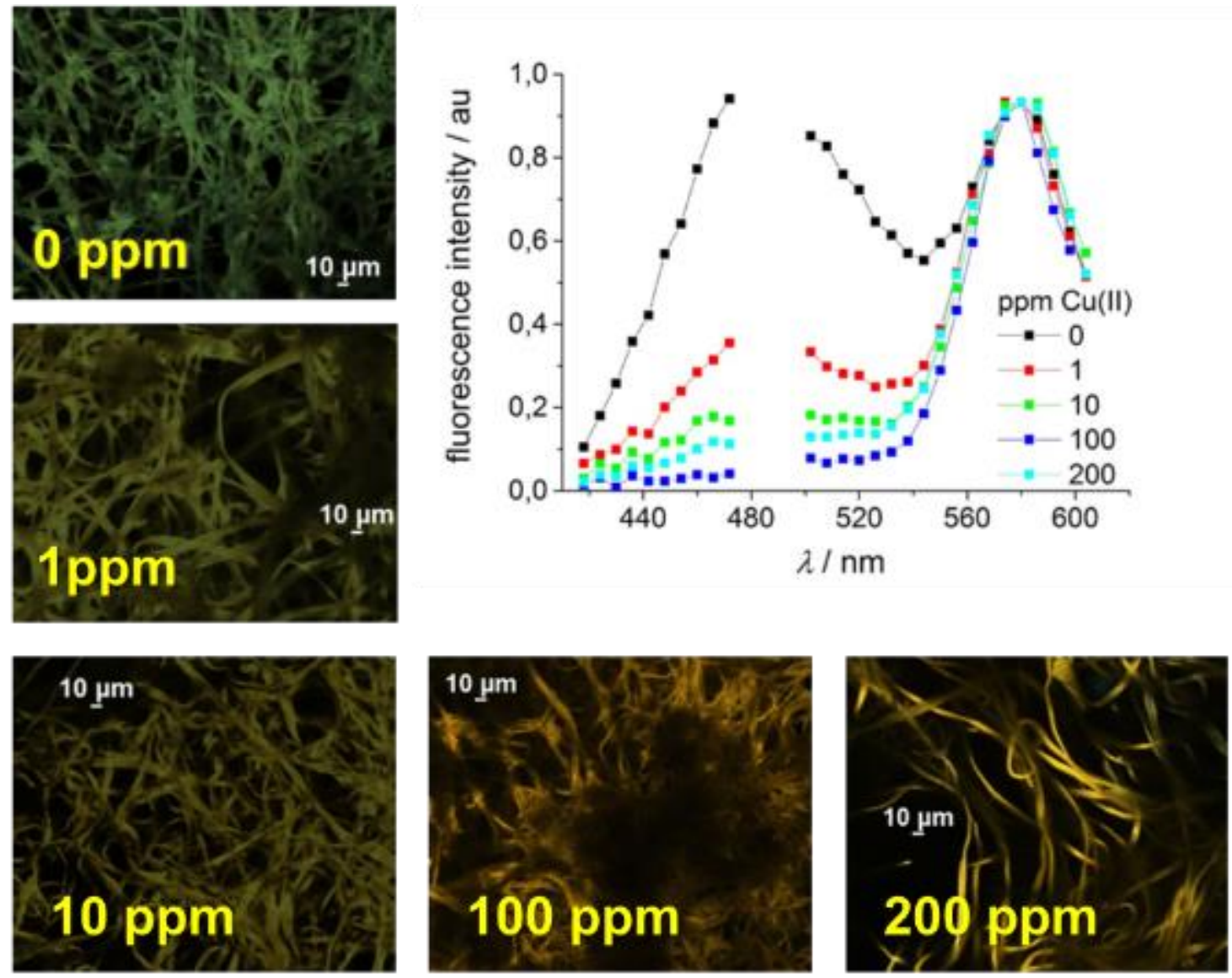

Figure 8. CLSM spectral images and graph with the confocal spectra obtained exciting at $405 \mathrm{~nm}$ for the fiber samples treated with different amounts of $\mathrm{Cu}$ (II) (due to a dichroic mirror reflecting light centered at $488 \mathrm{~nm}$ the spectra is not complete in the $480-500 \mathrm{~nm}$ range).

\section{Materials and Methods}

\subsection{Materials}

Cellulose acetate, dimethylformamide (DMF), dichloromethane (DCM), and acetone were from Sigma-Aldrich (St. Louis, MO, USA). Spectroscopic grade ethanol was from Carlo Erba (Barcelona, Spain). Rhodamine B (RB) was from Sigma-Aldrich (St. Louis, MO, USA) and Rhodamine B hydrazide $(\mathrm{RBH})$ was prepared according to a procedure previously reported [14].

\subsection{Film Preparation by Solution Casting}

The cellulose acetate solution in acetone was gently poured in uniform petri dishes with diameter of $10 \mathrm{~cm}$ and the films left to dry at room temperature. A transparent non-porous film was produced, which was preserved under dry conditions in a desiccator at room temperature till further use [29].

\subsection{Membrane Preparation by Phase Inversion}

Flat cellulose acetate porous membranes were prepared by phase inversion technique. A suitable amount of cellulose acetate solution in DMF (20 wt.\%) was poured on a glass plate and spread on the flat glass sheet surface by doctor knife. The produced uniform thin layer of cellulose acetate on the glass plate was dipped in deionized water smoothly. The formed oblique porous membrane was separated from water and preserved under dry conditions in a desiccator at room temperature till further use [30]. 


\subsection{Fabrication of Nanofibers by Electrospinning}

Cellulose acetate nanofibers were prepared by electrospinning using the following conditions: the polymer was dissolved in: (i) DMF and (ii) a DCM/acetone mixture in a concentration of $15 \%$ by weight and fed through a glass syringe attached with Teflon tube ended with a metallic needle, with a flow rate of $1 \mathrm{~mL} / \mathrm{h}$ in case of using DCM/acetone mixture and $0.5 \mathrm{~mL} / \mathrm{h}$ in case of using DMF. A potential difference of 16 and $21 \mathrm{KV}$ was applied between the needle and the metal collector in case of using $\mathrm{DMF} /$ acetone mixture and DMF, respectively. The distance between the needle and the collector was kept at $15 \mathrm{~cm}$ [15-17].

\subsection{RBH Pre-Loaded Fabrics}

The RBH dye was loaded onto the cellulose acetate matrix by solution mixing (pre- loading). A pre-prepared DMF solution of $\mathrm{RBH}$ was used as dope solution to be mixed with the CA solution in different weight percentages. Pre-loaded fabrics were prepared by solution casting, phase inversion or electrospinning using the same conditions as for preparation for pure cellulose acetate fabrics.

\subsection{RBH Post-Loaded Fabrics}

RBH was loaded onto the CA fabrics (casted films, porous membranes and fibers) after their fabrication by adding, step by step, an ethanol solution of $\mathrm{RBH}$ into the fabricated materials (cut as $25 \mathrm{~mm} \times 25 \mathrm{~mm}$ squares) and waiting for the complete evaporation of the solvent. Ethanol was chosen as an optimum solvent to allow a good solubilization of $\mathrm{RBH}$ without solubilizing the polymer.

The loading of $\mathrm{RBH}$ was performed on the basis of $w / w \%$ for the soft materials which could absorb completely the solution (phase deposition and fibers): two loadings have been tested: 0.5 and $1.0 \%$. For the casted films, where the solution was not absorbed and dried on the top of the film, an average volume of solution with respect to the other samples was used $(50 \mu \mathrm{L}$ of a solution 0.978 $\mathrm{mg} / \mathrm{mL}$, which corresponds to $0.049 \mathrm{mg} \mathrm{RBH}$ on the surface for $0.5 \%$ loading, and double amount for $1 \%$ loading).

\subsection{Morphological Characterization}

Field Emission Scanning Electron Microscopy (FE-SEM) images of the top surface of the fabrics were obtained using Quanta FEG 250, FEI Co., The Netherlands.

\subsection{Spectroscopic and Photophysical Characterization}

All measurements were performed at room temperature. Spectroscopic grade ethanol was from Carlo Erba (Barcelona, Spain). Rhodamine B was from Sigma-Aldrich (St. Louis, MO, USA) and Rhodamine B hydrazide was prepared according to a procedure previously reported [14]. Absorption spectra of solutions were acquired with a Perkin-Elmer Lambda $650 \mathrm{UV} /$ Vis spectrophotometer (Llantrisant, UK) in $1 \mathrm{~mm}$ optical path cuvettes. Reflectance spectra of solid samples were acquired with a Perkin-Elmer Lambda 950 UV/Vis/NIR spectrophotometer (Shelton, USA) equipped with a $100 \mathrm{~mm}$ integrating sphere. The samples were placed inside $25 \mathrm{~mm} \times 25 \mathrm{~mm}$ quartz slides. For the post-loaded samples, the spectra were measured on the face loaded with RBH. The spectra obtained after contact with $\mathrm{CuCl}_{2}$ solutions were normalized on the maximum of absorption of the polymer $(274 \mathrm{~nm})$ to minimize the scattering effects.

Emission spectra of solutions were acquired in right-angle geometry with an Edinburgh FLS920 fluorimeter (Edinburgh, UK) equipped with a Peltier-cooled Hamamatsu R928 PMT (200-850 nm) and corrected for the wavelength dependent phototube response. Emission spectra of solid samples were collected with the same fluorimeter in front-face mode.

Fluorescence lifetimes were determined with an IBH 5000F time-correlated single-photon counting apparatus (Edinburgh, UK) by using pulsed NanoLED excitation sources at 331 and $465 \mathrm{~nm}$. Analysis 
of the fluorescence decay profiles against time was accomplished with the Decay Analysis Software DAS6 provided by the manufacturer. The estimated error on lifetime determinations is $10 \%$.

\subsection{Fluorescence Confocal Laser Scanning Microscopy}

Fluorescence imaging was performed on an inverted Nikon Ti-E microscope (Nikon Co., Shinjuku, Japan). The confocal microscope Nikon A1 is equipped with an Argon ion CW laser as well as a 405 and $485 \mathrm{~nm}$ pulsed/CW diode lasers (PicoQuant GmbH, Berlin, Germany). Images were collected using a Nikon Plan Apo VC 60X oil immersion objective with NA 1.40. Filters were set to register the fluorescence in the $460-500 \mathrm{~nm}, 500-550 \mathrm{~nm}$, and 565-605 nm ranges. A Nikon A1 spectral module with a precisely corrected 32-channel multi-anode photomultiplier detector was used for spectral imaging. Wavelength resolution was set to $6 \mathrm{~nm}$ per anode. Spectral images were obtained by exciting the sample at $488 \mathrm{~nm}$ in CW mode. A dichroic mirror reflecting $405 \mathrm{~nm}$ and $488 \mathrm{~nm}$ excitation light was used during confocal imaging.

\subsection{Overview of the Studied Samples and Processes}

Table 1 summarizes the types of cellulose acetate materials studied, their preparation conditions, their loading with $\mathrm{RBH}$ and the parameters adopted for $\mathrm{Cu}(\mathrm{II})$ sensing.

Table 1. Summary of the sample preparation procedures, dye loading, and $\mathrm{Cu}(\mathrm{II})$ sensing.

\begin{tabular}{|c|c|c|c|c|c|c|}
\hline Sample & $\begin{array}{l}\text { Solvent(s) } \\
\text { Used for } \\
\text { Preparation }\end{array}$ & $\begin{array}{l}\text { Preparation } \\
\text { Procedure }\end{array}$ & $\begin{array}{c}\text { Loading } \\
\text { with RBH } \\
(w / w \%)^{a}\end{array}$ & $\begin{array}{c}\text { Immersion } \\
\text { Time with } \\
\text { Cu(II) Solution }\end{array}$ & $\begin{array}{l}\mathrm{pH} \text { of the } \\
\mathrm{Cu}(\mathrm{II}) \\
\text { Solution }\end{array}$ & $\mathrm{Cu}(\mathrm{II})$ Concentration \\
\hline \multirow{2}{*}{ Casted film } & \multirow{2}{*}{ Acetone } & \multirow{2}{*}{ Casting } & $0.50 \%$ & - & - & - \\
\hline & & & $1.00 \%$ & - & - & - \\
\hline \multirow{2}{*}{ Membrane } & \multirow{2}{*}{ Acetone/DMF } & \multirow{2}{*}{ Phase inversion } & $0.50 \%$ & - & - & - \\
\hline & & & $1.00 \%$ & 1 night & 7 & $1,10,100$, and $200 \mathrm{ppm}$ \\
\hline \multirow{2}{*}{ Nanofibers } & \multirow{2}{*}{ DMF } & \multirow{2}{*}{ Electrospinning } & $0.50 \%$ & - & - & - \\
\hline & & & $1.00 \%$ & 1 night & 7 & $1,10,100$, and $200 \mathrm{ppm}$ \\
\hline \multirow{2}{*}{ Nanofibers } & \multirow{2}{*}{ DCM/Acetone } & \multirow{2}{*}{ Electrospinning } & $0.50 \%$ & - & - & - \\
\hline & & & $1.00 \%$ & 1 night & 7 & $1,10,100$, and $200 \mathrm{ppm}$ \\
\hline
\end{tabular}

\section{Conclusions}

Rhodamine B hydrazide was successfully loaded into cellulose acetate, a natural polymer derivative. Among the prepared samples, the most suitable fabrics for RBH loading were the porous phase-deposited membrane and two types of nanofibers, differing in the fiber diameter.

The post-treatment deposition, where the dye is loaded after the preparation of the polymeric material, ensured good stability with respect to degradation and the dye retained the optical properties observed in solution.

Optimized RBH loading occurred at 1\% $(w / w)$ for both the porous membrane and the nanofibers. The selected samples were then tested for $\mathrm{Cu}$ (II) sensing affording a satisfactory response, especially in terms of colorimetric detection. Nanofibers electrospun from DCM/acetone and loaded with RBH were found to be the most sensitive fabric towards $\mathrm{Cu}$ (II). Further studies on the sensitivity and selectivity of this composite material are under way. These promising results open the way to the development of bio-compatible and ready-to-use sensing systems. 
Supplementary Materials: The following are available online, Figure S1: Arbitrarily scaled absorption (full line, $\varepsilon / \mathrm{M}^{-1} \mathrm{~cm}^{-1}: 59,400$ at $240 \mathrm{~nm}, 36,500$ at $273 \mathrm{~nm}$, and 13,300 at $312 \mathrm{~nm}$ ) and emission (dashed line) spectra of RBH in ethanol at room temperature; Figure S2: Arbitrarily scaled absorption (full line) and emission (dashed line) spectra of RB in ethanol at room temperature; Figure S3. Absorption spectra of samples with 0, 0.5, and 1\% (w/w) post-loading of RBH: (a) casted film, (b) phase deposited membrane, (c) fibers from DMF, and(d) fibers from DCM/acetone; Figure S4: Corrected emission spectra of samples with 0, 0.5, and 1\% (w/w) post-loading of RBH: (a) casted film, (b) phase deposited membrane, (c) fibers from DMF, and (d) fibers from DCM/acetone. Excitation at $320 \mathrm{~nm}$; Figure S5: Normalized corrected excitation spectra, collected at $430 \mathrm{~nm}$, for fibers from DMF (full line) and fibers from DCM/acetone (dashed line); Figure S6: Corrected excitation spectra, collected at 500 and $600 \mathrm{~nm}$, for phase deposited membrane sample loaded with 1\% RBH; Figure S7. Absorption spectra of the RBH loaded polymeric materials, prior and after 1 night immersion in $\mathrm{CuCl}_{2}$ water solutions $(\mathrm{pH}=7)$ at different $\mathrm{Cu}$ (II) concentrations: (a) porous membrane, (b) fibers from DMF, and (c) fibers from DCM/acetone. In the insets, a magnification of the $400-780 \mathrm{~nm}$ region is reported; Figure S8: Ratios of emission intensity at $584 \mathrm{vs}$. $470 \mathrm{~nm}$, as a function of $\mathrm{Cu}$ (II) concentration, collected upon excitation at $320 \mathrm{~nm}$ for: phase deposited membrane (black), fibers from DMF (red), fibers from DCM/acetone (blue), loaded with $1 \% \mathrm{RBH}$, after contact with $\mathrm{CuCl}_{2}$ water solutions $(\mathrm{pH}=7)$; Figure S9: Corrected emission spectra, collected upon excitation at $480 \mathrm{~nm}$, of the materials loaded with $1 \% \mathrm{RBH}$ after contact with $\mathrm{CuCl}_{2}$ water solutions $(\mathrm{pH}=7)$ at different $\mathrm{Cu}$ (II) concentrations: (a) phase deposited membrane, (b) fibers from DMF, and (c) fibers from DCM/acetone. In (a) the purple and pink spectra have been divided by 5; Figure S10: Arbitrarily scaled corrected excitation spectra, collected at $620 \mathrm{~nm}$ and $750 \mathrm{~nm}$, for fibers from DCM/acetone loaded with $1 \% \mathrm{RBH}$ after contact with $200 \mathrm{ppm} \mathrm{CuCl} 2$ water solution $(\mathrm{pH}=7)$; Table S1: Lifetimes measured on solid materials, upon excitation at $331 \mathrm{~nm}$, at the indicated wavelengths; Figure S11: The graphs show six normalized confocal fluorescence spectra of various regions of interest collected from each spectral image below. The images at the bottom represent the fluorescence intensity ratio $\mathrm{I}_{585} \mathrm{~nm} / \mathrm{I}_{480} \mathrm{~nm}$ ranging from 0,1 (purple) to 3 (red).

Author Contributions: Data curation, R.E.M. and B.V.; Investigation, R.E.M., M.E., I.M., and B.V.; Methodology, R.E.M., M.E., I.M., and B.V.; Writing-original draft, R.E.M., I.M., and B.V.; Writing一review \& editing, R.E.M., M.E., I.M., and B.V. All authors have read and agreed to the published version of the manuscript.

Funding: H2020-MSCA-IF-800317 Project “Enhanced-MUMs", National Research Council (CNR-Italy)—Academy of Scientific Research \& Technology (ASRT-Egypt) Bilateral Cooperation Project "FLUO-NanoFAB" and Italian CNR (project "PHEEL") are greatly acknowledged.

Conflicts of Interest: The authors declare no conflict of interest. The funders had no role in the design of the study; in the collection, analyses, or interpretation of data; in the writing of the manuscript, or in the decision to publish the results.

Notes: $\S$ The reflectance spectrum of the bare polymeric material in the $230-320 \mathrm{~nm}$ range has been omitted because higher than $100 \%$, probably due to scattering effects of the porous membrane.

\section{References}

1. National Research Council (US) Committee on Copper in Drinking Water. Copper in Drinking Water. Washington (DC): National Academies Press (US); 2000. 5, Health Effects of Excess Copper. Available online: https://www.ncbi.nlm.nih.gov/books/NBK225400/ (accessed on 30 June 2020).

2. Chen, X.; Pradhan, T.; Wang, F.; Kim, J.S.; Yoon, J. Fluorescent Chemosensors Based on Spiroring-Opening of Xanthenes and Related Derivatives. Chem. Rev. 2011, 112, 1910-1956. [CrossRef] [PubMed]

3. Rai, A.; Singh, A.; Tripathi, K.; Sonkar, A.K.; Chauhan, B.S.; Srikrishna, S.; James, T.D.; Mishra, L. A quick and selective rhodamine based "smart probe" for "signal-on" optical detection of $\mathrm{Cu} 2+$ and $\mathrm{Al} 3+$ in water, cell imaging, computational studies and solid state analysis. Sensors Actuat. B Chem. 2018, 266, 95-105. [CrossRef]

4. Yu, C.; Zhang, J.; Wang, R.; Chen, L. Highly sensitive and selective colorimetric and off-on fluorescent probe for $\mathrm{Cu} 2+$ based on rhodamine derivative. Org. Biomol. Chem. 2010, 8, 5277-5279. [CrossRef] [PubMed]

5. López, M.T.; Pablos, J.L.; Muñoz, M.A.; Ibeas, S.; Serna, F.; García, F.C.; García, J.M. Aromatic polyamides and acrylic polymers as solid sensory materials and smart coated fibres for high acidity colorimetric sensing. Polym. Chem. 2015, 6, 3110-3120. [CrossRef]

6. Favaretto, L.; Manoli, F.; Zambianchi, M.; Bocchi, L.; Ventura, B.; Manet, I.; Melucci, M. Immobilization of Perylene-3,4,9,10-Tetracarboxylic Dianhydride on Hollow Polysulfone Fibers: Primary Amine Coupling and Fluorescence Reporting. ChemPlusChem 2019, 84, 1299-1304. [CrossRef]

7. Tao, C.; Ying, Y.-M.; Wang, H.; Chen, B.; Zhu, G.-P.; Song, Y.-J.; Liu, X.-G.; Zhao, Z.; Shen, L.; Tang, B.Z. Nonwoven fabric coated with a tetraphenylethene-based luminescent metal-organic framework for selective and sensitive sensing of nitrobenzene and ammonia. J. Mater. Chem. C 2018, 6, 12371-12376. [CrossRef] 
8. $\quad$ Liang, C.Z.; Chung, T.-S.; Lai, J.-Y. A review of polymeric composite membranes for gas separation and energy production. Prog. Polym. Sci. 2019, 97, 101141. [CrossRef]

9. Hołda, A.K.; Vankelecom, I.F. Understanding and guiding the phase inversion process for synthesis of solvent resistant nanofiltration membranes. J. Appl. Polym. Sci. 2015, 132, 42130. [CrossRef]

10. Rodríguez-Tobías, H.; Morales, G.; Grande, D. Comprehensive review on electrospinning techniques as versatile approaches toward antimicrobial biopolymeric composite fibers. Mater. Sci. Eng. C 2019, 101, 306-322. [CrossRef]

11. Abrigo, M.; McArthur, S.L.; Kingshott, P. Electrospun Nanofibers as Dressings for Chronic Wound Care: Advances, Challenges, and Future Prospects. Macromol. Biosci. 2014, 14, 772-792. [CrossRef]

12. Bedford, N.M.; Steckl, A.J. Photocatalytic Self Cleaning Textile Fibers by Coaxial Electrospinning. ACS Appl. Mater. Interfaces 2010, 2, 2448-2455. [CrossRef]

13. Abdal-Hay, A.; Makhlouf, A.S.H.; Khalil, K.A.; Hamdy, A.S. Novel, Facile, Single-Step Technique of Polymer/TiO2Nanofiber Composites Membrane for Photodegradation of Methylene Blue. ACS Appl. Mater. Interfaces 2015, 7, 13329-13341. [CrossRef] [PubMed]

14. Morsi, R.E.; ElSawy, M.A.; Ali, M.M.; Gentili, D.; Cavallini, M.; Manet, I.; Bandini, E.; Venturini, A.; Benaglia, M.; Ventura, B. Rhodamine B hydrazide loaded polysulfone fabrics for $\mathrm{Cu}(\mathrm{II})$ detection: Morphological and optical properties. J. Appl. Polym. Sci. 2019, 137, 48408. [CrossRef]

15. Tungprapa, S.; Puangparn, T.; Weerasombut, M.; Jangchud, I.; Fakum, P.; Semongkhol, S.; Meechaisue, C.; Supaphol, P. Electrospun cellulose acetate fibers: Effect of solvent system on morphology and fiber diameter. Cellulose 2007, 14, 563-575. [CrossRef]

16. Han, S.O.; Youk, J.H.; Min, K.D.; Kang, Y.O.; Park, W.H. Electrospinning of cellulose acetate nanofibers using a mixed solvent of acetic acid/water: Effects of solvent composition on the fiber diameter. Mater. Lett. 2008, 62, 759-762. [CrossRef]

17. Cai, J.; Niu, H.; Yu, Y.; Xiong, H.; Lin, T. Effect of solvent treatment on morphology, crystallinity and tensile properties of cellulose acetate nanofiber mats. J. Text. Inst. 2016, 108, 1-8. [CrossRef]

18. Kristoffersen, A.S.; Erga, S.R.; Hamre, B.; Frette, $\varnothing$. Testing Fluorescence Lifetime Standards using Two-Photon Excitation and Time-Domain Instrumentation: Rhodamine B, Coumarin 6 and Lucifer Yellow. J. Fluoresc. 2014, 24, 1015-1024. [CrossRef] [PubMed]

19. Sadkowski, P.; Fleming, G. Photophysics of the acid and base forms of rhodamine B. Chem. Phys. Lett. 1978, 57, 526-529. [CrossRef]

20. Arbeloa, T.L.; Estévez, M.T.; Arbeloa, F.L.; Aguirresacona, I.U.; López-Arbeloa, I. Luminescence properties of rhodamines in water/ethanol mixtures. J. Lumin. 1991, 48, 400-404. [CrossRef]

21. Tungsombatvisit, N.; Inprasit, T.; Rohmawati, D.; Pisitsak, P. Rhodamine Derivative- Based Cellulose Acetate Electrospun Colorimetric Sensor for Cu2+ Sensing in Water: Effects of Alkaline Treatment. Fibers Polym. 2019, 20, 481-489. [CrossRef]

22. Silva, A.; Boto, R.E.; El-Shishtawy, R.M.; Almeida, P. Rhodamine B as ligand for affinity chromatography. Fixation studies onto cellulose by a curing method. Eur. Polym. J. 2006, 42, 2270-2282. [CrossRef]

23. Che, M.; Védrine, J.C. Characterization of Solid Materials and Heterogeneous Catalysts: From Structure to Surface Reactivity; Wiley-VCH Verlag GmbH \& Co. KGaA: New York, NY, USA, 2012; Volume 1.

24. Lewkowicz, A.; Synak, A.; Grobelna, B.; Kułak, L.; Bojarski, P. Spectroscopic properties of Rhodamine B entrapped in hybrid porous nanolayers at high dye concentration. Chem. Phys. 2014, 439, 121-127. [CrossRef]

25. Pasini, D.; Takeuchi, D. Cyclopolymerizations: Synthetic Tools for the Precision Synthesis of Macromolecular Architectures. Chem. Rev. 2018, 118, 8983-9057. [CrossRef] [PubMed]

26. Zhang, X.-F.; Zhang, Y.-K. Long-lived and largely red-shifted photoluminescence of solid-state rhodamine dyes: Molecular exciton coupling and structural effect. J. Lumin. 2015, 166, 215-221. [CrossRef]

27. Kawahigashi, M.; Hirayama, S. Microscopic fluorescence decay measurements on thin liquid films and droplets of concentrated dye solutions. J. Lumin. 1989, 43, 207-212. [CrossRef]

28. Sakai, Y.; Kawahigashi, M.; Minami, T.; Inoue, T.; Hirayama, S. Deconvolution of non-exponential emission decays arising from reabsorption of emitted light. J. Lumin. 1989, 42, 317-324. [CrossRef] 
29. Tedeschi, G.; Guzman-Puyol, S.; Paul, U.C.; Barthel, M.J.J.; Goldoni, L.; Caputo, G.; Ceseracciu, L.; Athanassiou, A.; Heredia-Guerrero, J.A. Thermoplastic cellulose acetate oleate films with high barrier properties and ductile behaviour. Chem. Eng. J. 2018, 348, 840-849. [CrossRef]

30. Ghaseminezhad, S.M.; Barikani, M.; Salehirad, M. Development of graphene oxide-cellulose acetate nanocomposite reverse osmosis membrane for seawater desalination. Compos. Part B Eng. 2019, 161, 320-327. [CrossRef]

Sample Availability: Samples of the compounds are not available from the authors.

(C) 2020 by the authors. Licensee MDPI, Basel, Switzerland. This article is an open access article distributed under the terms and conditions of the Creative Commons Attribution (CC BY) license (http://creativecommons.org/licenses/by/4.0/). 